\title{
Catalytic asymmetric synthesis of the common amino acid component in the biosynthesis of tetrahydroisoquinoline alkaloids
}

\author{
Ryo Tanifuji ${ }^{\mathrm{a}}$, Hiroki Oguri, ${ }^{\mathrm{a}, \mathrm{b}, \mathrm{c}, *}$ Kento Koketsu ${ }^{\mathrm{a}}$, Yuki Yoshinaga ${ }^{\mathrm{a}}$, Atsushi Minami ${ }^{\mathrm{a}}$, Hideaki Oikawa $^{\mathrm{a}, *}$ \\ ${ }^{a}$ Division of Chemistry, Graduate School of Science, Hokkaido University, North 10 West 8, Sapporo 060-0810, Japan. \\ ${ }^{b}$ Division of Applied Chemistry, Graduate School of Engineering, Tokyo University of Agriculture and Technology, 2-24-16 Nakacho, Koganei, Tokyo 184-8588, \\ Japan \\ 'Japan Science and Technology Agency (JST) PRESTO, 4-1-8 Honcho, Kawaguchi, Saitama 332-0012, Japan
}

\section{ARTICLE INFO}

\section{ABSTRACT}

\section{Article history:}

Received

Received in revised form

Accepted

Available online

\section{Keywords:}

tetrahydroisoquinoline alkaloid

tyrosine derivative

catalytic asymmetric synthesis

common biosynthetic precursor
Biosynthetic assembly lines of tetrahydroisoquinoline alkaloids employ the tyrosine derivative, $(S)$-2-amino-3-(3-hydroxy-4-methoxy-5-methylphenyl)propanoic acid, as a common amino acid building block. A catalytic asymmetric synthetic route to the common amino acid component has been developed by making use of Maruoka's chiral phase transfer alkylation of a glycine derivative with the requisite benzyl bromide.

A family of tetrahydroisoquinoline antitumor antibiotics has attracted considerable attention due to their potent antiproliferative activities as well as intricate molecular architectures (Fig.1). ${ }^{1}$ These naturally occurring alkaloids, including saframycins $\mathbf{1}^{2}$ safracins $\mathbf{2}^{3}$ jorumycins $\mathbf{3}$, naphthyridinomycins/cyanocyclines $\mathbf{4}^{4,5}$ and ecteinascidins $\mathbf{5},{ }^{6}$ share tetrahydroisoquinoline substructures assembled by nonribosomal peptide synthetases (NRPSs). Our recent studies on saframycin A (1) revealed remarkable characteristics of the biosynthetic machinery that incorporates two molecules of a

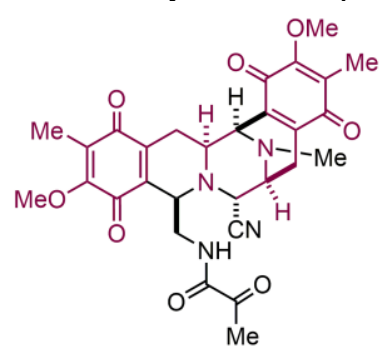

saframycin A (1)

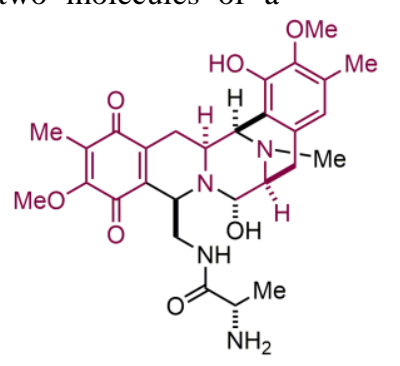

safracin $B(2): R=O H$ tyrosine derivative 6 as a common precursor to form the tetrahydroisoquinoline substructures. ${ }^{7}$ Apart from the conventional NRPS assembly lines forming the amide linkage, SfmC, a key module for the biosynthesis of $\mathbf{1}$, catalyzes the formation of $\mathrm{sp}^{3}$ stereogenic centers of the tetrahydroisoquinoline rings through a unique mechanism involving the $\mathrm{R}$ domainmediated reductions of thioesters and the subsequent $\mathrm{C}$ domaincatalyzed Pictet-Spengler type cyclizations ${ }^{8}$ that iteratively incorporate the tyrosine derivative 6 (Scheme 1).

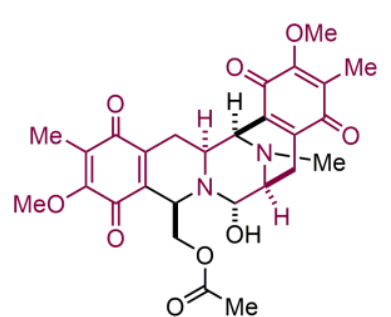

jorumycin (3)

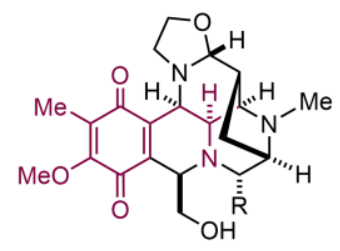

naphthyridinomycin (4)

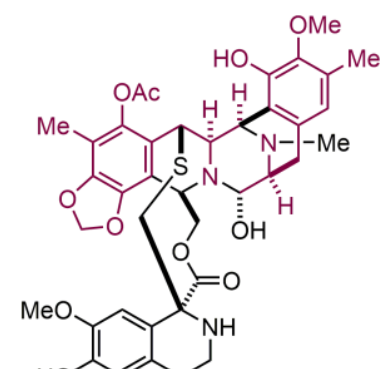

ecteinascidin $743(5)$

Figure 1. Tetrahydroisoquinoline alkaloids 1-5, a proposed common precursor 6 for biosynthesis, and more oxygenated derivative 7. 
Our research group accomplished the chemo-enzymatic synthesis of the core scaffold $\mathbf{8}$ of $\mathbf{1}$ through the SfmC-catalyzed conversion of the synthetic precursors, the tyrosine derivative 6 and an acyl peptidyl aldehyde, followed by amino nitrile formation upon treatment with $\mathrm{KCN}$ (Scheme 1). ${ }^{7}$ As of this moment, the maximum amount of the enzymatic conversion yielding $\mathbf{8}$ is in the range of several milligrams. To substantially improve the production efficiency of the naturally occurring scaffold and its variants, concise synthesis of $\mathbf{6}$, the common amino acid component shared among the families of tetrahydroisoquinoline alkaloids, has remained as an important task.
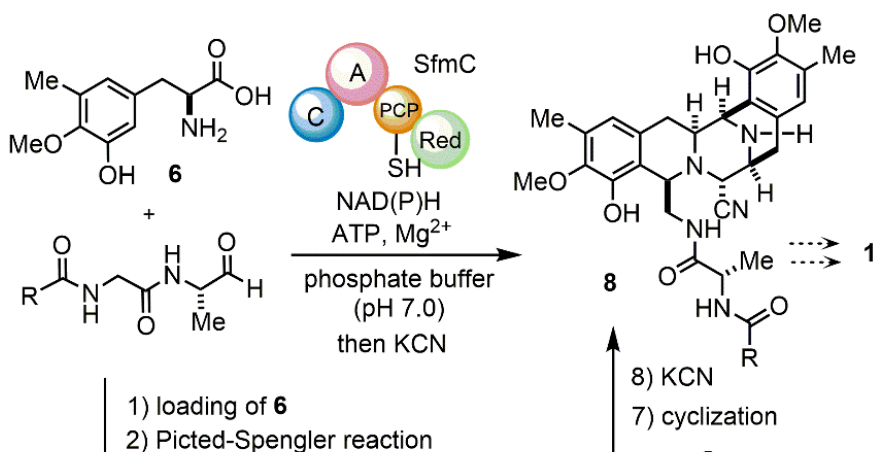

2) Picted-Spengler reaction
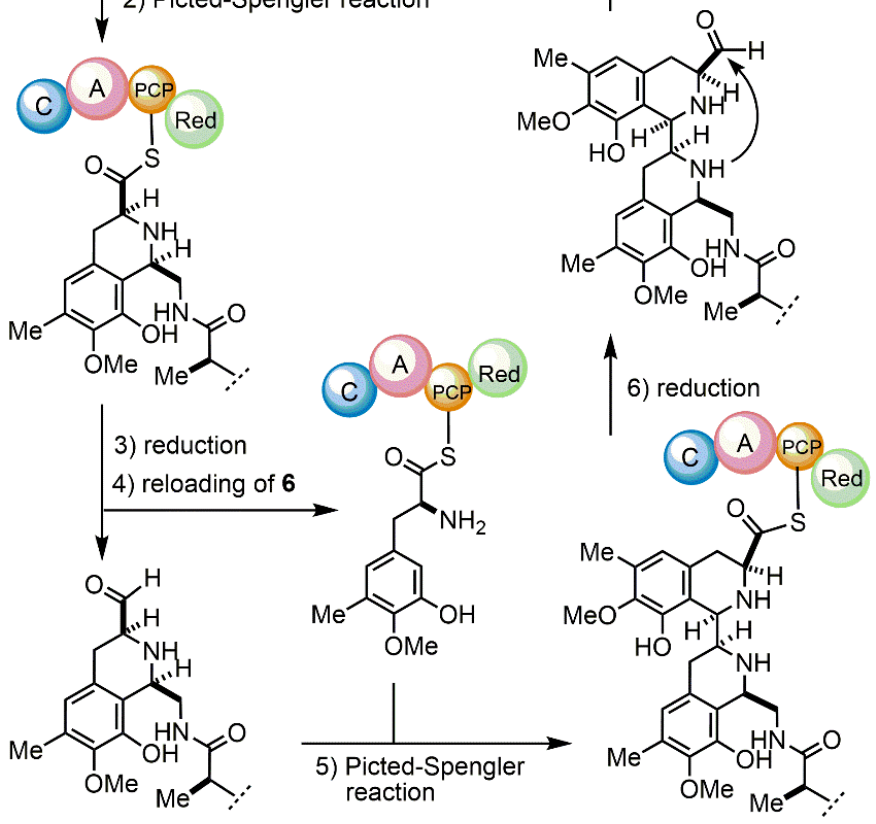

Scheme 1. (a) Outline of the chemo-enzymatic synthesis with proposed mechanism for SfmC-catalyzed formation of the core scaffold $\mathbf{8}$ of $\mathbf{1}$.

Synthetic studies on the functionalized tyrosine derivative $\mathbf{6}$, and more oxygenated 7 as a precursor for the corresponding quinone substructure in natural products $\mathbf{1 - 4}$, fall into three different approaches. ${ }^{9}$ The first one, represented by Schmidt's report, ${ }^{10}$ is the conversion of either L-DOPA or L-tyrosine utilizing a formylation/oxidation protocol ${ }^{11}$ and iodination followed by Stille coupling to install the phenol and methyl groups of $\mathbf{6}$, respectively. ${ }^{12}$ The second approach employs the rhodium-catalyzed asymmetric hydrogenation of the corresponding alkene to incorporate the amino acid functional groups. ${ }^{13}$ The third approach adopts a convergent assembly through alkylation of a glycine derivative with benzyl halide. ${ }^{14}$ Jin and Williams ${ }^{15}$ developed a nine-step synthetic route featuring diastereoselective alkylation utilizing a chiral ozaxinone as the glycine unit. Zhu and co-workers ${ }^{16}$ reported an enantioselective alkylation employing Corey's chiral quaternary ammonium salt of a cinchona alkaloid derivative. ${ }^{17}$
Herein, we describe the development of a catalytic asymmetric synthetic route featuring an enantioselective alkylation of the glycine derivative $\mathbf{1 1}$ with $\mathbf{1 0}$ employing Maruoka's phase transfer catalyst, ${ }^{18,19}$ which allows for concise access to $\mathbf{6}$ in eight steps from 3-methyl catechol 9 (Scheme 2).

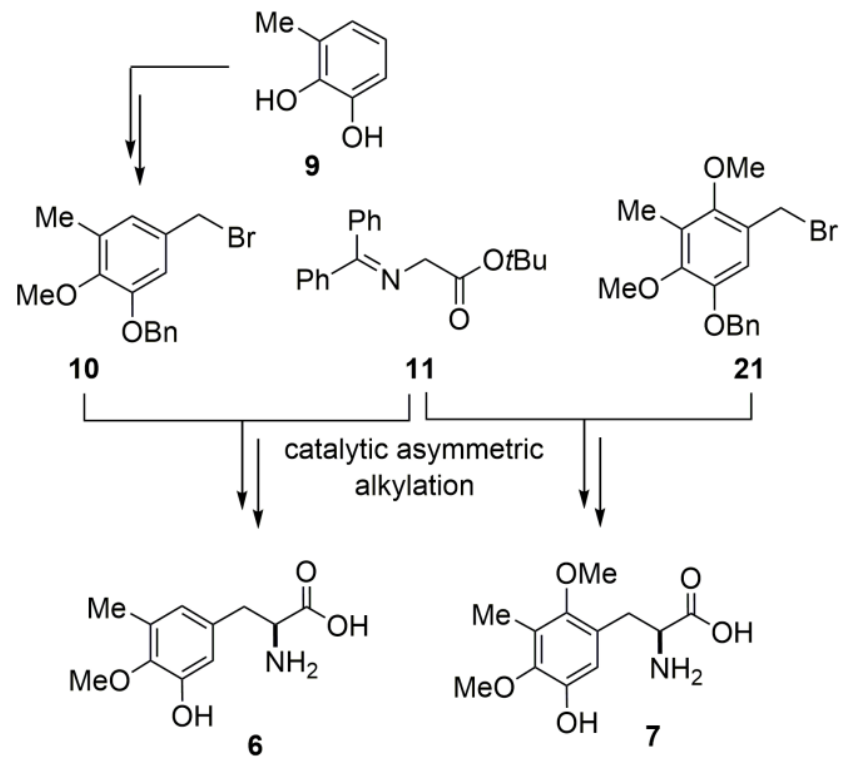

Scheme 2. Outline of the synthesis of 6 . and 7.

Synthesis of the benzyl bromide $\mathbf{1 0}$ commenced with the commercially available 3-methyl catechol 9 (Scheme 3). Upon treatment of 9 with benzyl chloride in the presence of $\mathrm{NaI}$ and $\mathrm{NaHCO}_{3}$ in refluxing acetonitrile, site-selective benzylation of the catechol system proceeded to form $\mathbf{1 2}$ as the major product. Because of the difficulty in separating the regioisomers and the dibenzylated byproduct, the resulting mixture was directly subjected to formylation with hexamethylenetetramine (HMTA) in acetic acid at $100{ }^{\circ} \mathrm{C} .{ }^{20}$ The formylation reaction occurred in a highly regio-controlled manner, and the desired aldehyde $\mathbf{1 3}$ was obtained in a moderate yield (30\% in 2 steps) after separation of the corresponding regioisomers and dibenzylated byproduct. Methylation of the remaining phenolic hydroxyl group and subsequent reduction of the aldehyde with $\mathrm{NaBH}_{4}$ produced 14 in high yield. Substitution of the alcohol 14 by treatment with $\mathrm{CBr}_{4}$ and $\mathrm{PPh}_{3}$ furnished the key intermediate 10. Due to instability of the benzyl bromide $\mathbf{1 0}$ bearing electron donating substituents in the aromatic ring, $\mathbf{1 0}$ was immediately used for the next step. The asymmetric alkylation of the glycine derivative $\mathbf{1 1}$ with $\mathbf{1 0}$ employing $(R)$-Maruoka's catalyst $\mathbf{1 5}^{19 \mathrm{c}}(0.5 \mathrm{~mol} \%)$ produced $\mathbf{1 6}$ in $77 \%$ yield for two steps. Treatment of $\mathbf{1 6}$ under acidic conditions in the presence of dimethyl sulfide as a scavenger for $t$-butyl cation or isobutylene allowed efficient removal of the protecting groups on the amino acid moiety to give 17. At this stage, we determined the enantiomeric excess of the alkylated product as $99 \%$ ee according to the advanced Marfey's method based on HPLC analysis of the diastereomeric 1-fluoro-2,4dinitrophenyl-5-L-leucinamide (L-FDLA) derivatives as shown in Scheme 4. ${ }^{21}$ The desired amino acid 6 was liberated by palladium-catalyzed hydrogenolysis in $66 \%$ yield for two steps. 


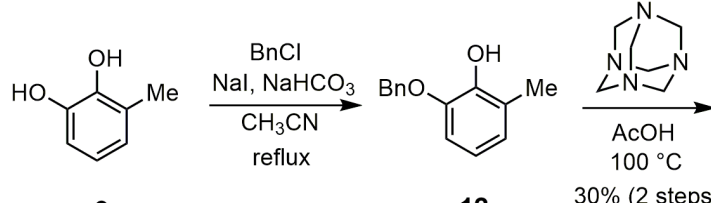

9<smiles>Cc1cc(C=O)cc(OCc2ccccc2)c1O</smiles>

13

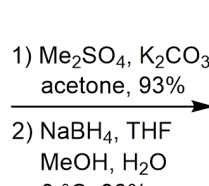

$0{ }^{\circ} \mathrm{C}, 98 \%$<smiles>COc1c(C)cc(CO)cc1OCc1ccccc1</smiles>

14

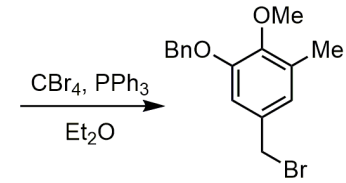

10

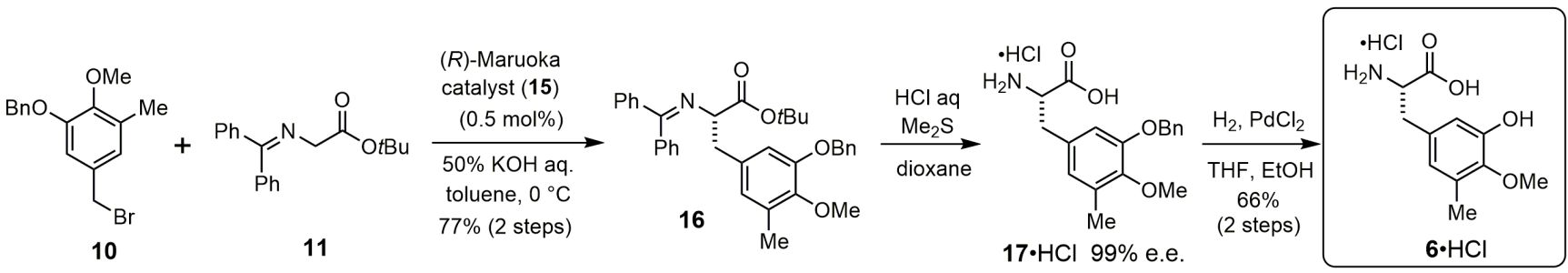

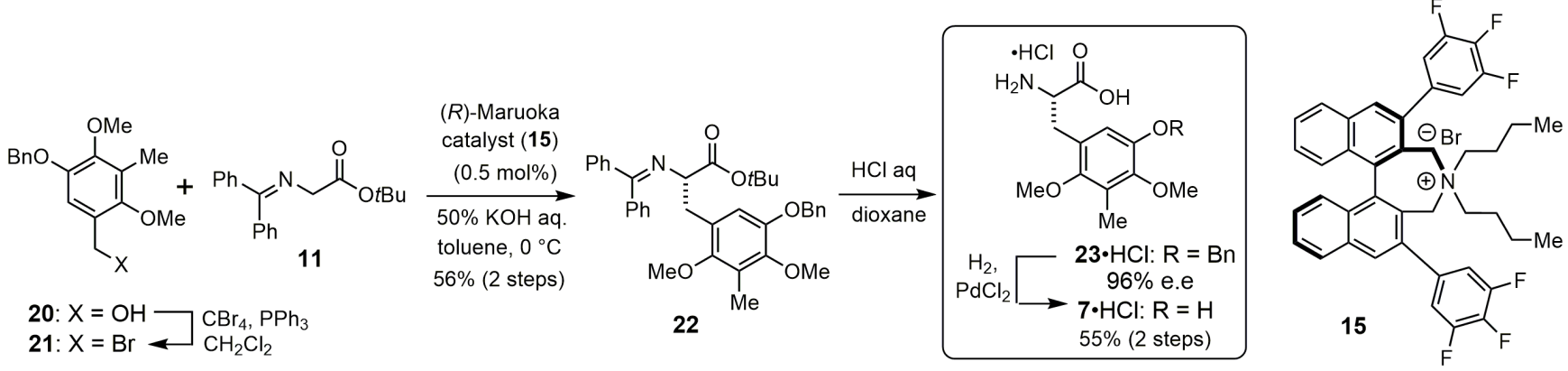

Scheme 3. Catalytic asymmetric synthetic of the tyrosine derivative 6 and

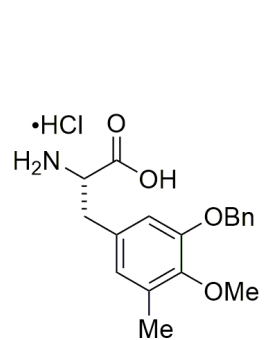

$17 \cdot \mathrm{HCl}$ 99\% e.e.<smiles>CC(C)C[C@H](C)C(N)=O</smiles><smiles>CNc1cc(F)c([N+](=O)[O-])cc1[N+](=O)[O-]</smiles>

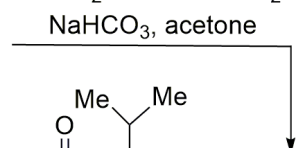<smiles></smiles>

C analysis of diastereomers<smiles></smiles>

Scheme 4. Formation of L-FDLA derivatives for determination of enantiomeric excess of $\mathbf{1 7}$ according to advanced Marfey's method.

This approach was then adopted to access a more functionalized tyrosine derivative $\mathbf{7}$, utilizing the corresponding benzyl alcohol $\mathbf{2 0}^{22}$ (Scheme 3 ). The catalytic asymmetric alkylation of $\mathbf{1 1}$ with $\mathbf{2 1}$ bearing additional functional group also proceeded smoothly at $0{ }^{\circ} \mathrm{C}$ to afford 22 in $56 \%$ yield (2 steps). In a similar way, the enantiomeric excess $(96 \%$ ee) was determined applying the advanced Marfey's method. Removal of protecting groups afforded the tyrosine derivative 7 .

In conclusion, we have developed a catalytic asymmetric synthetic route to the functionalized tyrosine derivatives $\mathbf{6}$ and $\mathbf{7}$, which allows operationally simple access to the key amino acid component with excellent enantioselectivity. By making use of $\mathbf{6}$ and $\mathbf{7}$ as the key amino acid building block, further investigations for chemo-enzymatic synthesis of tetrahydroisoquinoline alkaloids $^{23}$ are underway in our laboratories.

\section{Acknowledgements}

We are grateful for financial support from the Japan Science and Technology Agency (JST) "Precursory Research for Embryonic Science and Technology (PRESTO)" for a project of "Molecular technology and creation of new functions" (Grant No. 13416820) to H. Oguri, and JSPS KAKENHI (Grant No. 22108002) to H. Oikawa.

\section{References and notes}

1 Scott, J. D.; Williams, R. M. Chem. Rev. 2002, 102, 1669.

2 Li, L.; Deng, W.; Song, J.; Ding, W.; Zhao, Q.-F.; Peng, C.; Song, W.-W.; Tang, G.-L.; Liu, W. J. Bacteriol. 2008, 190, 251

3 Velasco, A.; Acebo, P.; Gomez, A.; Schleissner, C.; Rodriguez, P.; Aparicio, T.; Conde, S.; Munoz, R.; De la Calle, F.; Garcia, J. L.; Sanchez-Puelles, J. M. Mol. Microbiol. 2005, 56,144

4 Hiratsuka, T.; Koketsu, K.; Minami, A.; Kaneko, S.; Yamazaki, C.; Watanabe, K.; Oguri, H.; Oikawa, H. Chem. Biol. 2013, 20, 1523.

5 (a) Peng, C.; Pu, J.-Y.; Song, L.-Q.; Jian, X.-H.; Tang, M.-C.; Tang, G.-L. Proc. Natl. Acad. Sci. U. S. A. 2012, 109, 8540; (b) Pu, J.-Y.; Peng, C.; Tang, M.-C.; Zhang, Y.; Guo, J.-P.; Song, L.-Q.; Hua, Q.; Tang, G.-L. Org. Lett. 2013, 15, 3674.

6 Rath, C. M.; Janto, B.; Earl, J.; Ahmed, A.; Hu, F. Z.; Hiller, L.; Dahlgren, M.; Kreft, R.; Yu, F.; Wolff, J. J.; Kweon, H. K.; Christiansen, M. A.; Hakansson, K.; Williams, R. M.; Ehrlich, G. D.; Sherman, D. H. ACS Chem. Biol. 2011, 6, 1244.

7 (a) Koketsu, K.; Watanabe, K.; Suda, H.; Oguri, H.; Oikawa, H. Nat. Chem. Biol. 2010, 6, 408; (b) Koketsu, K.; Minami, A.; Watanabe, K.; Oguri, H.; Oikawa, H. Curr. Opin. Chem. Biol. 
2012, 16, 142; (c) Koketsu, K.; Minami, A.; Watanabe, K.; Oguri, H.; Oikawa, H. Methods Enzymol. 2012, 516, 79.

8 Stockigt, J.; Antonchick, A. P.; Wu, F.-R.; Waldmann, H. Angew. Chem., Int. Ed. 2011, 50, 8538.

9 Other synthetic approaches to the functionalized tyrosine derivatives 6 and 7, see: (a) Zhou, B.; Edmondson, S.; Padron, J.; Danishefsky, S. J. Tetrahedron Lett. 2000, 41, 2039; (b) Wu, Y.-C.; Zhu, J. Org. Lett. 2009, 11, 5558.

10 Schmidt, E. W.; Nelson, J. T.; Fillmore, J. P. Tetrahedron Lett. 2004, 45, 3921.

11 Jung, M. E.; Lazarova, T. I. J. Org. Chem. 1997, 62, 1553.

12 (a) Liao, X. W.; Liu, W.; Dong, W. F.; Guan, B. H.; Chen, S. Z.; Liu, Z. Z. Tetrahedron 2009, 65, 5709; (b) Chen, R.; Zhu, D.; Hu, Z.; Zheng, Z.; Chen, X. Tetrahedron: Asymmetry 2010, 21, 39; (c) Torikai, K.; Saruwatari, T.; Kitano, T.; Sano, T.; Nakane, A.; Noguchi, H.; Watanabe, K. Lett. Org. Chem. 2011, 8, 686 .

13 (a) Corey, E. J.; Gin, D. Y.; Kania, R. S. J. Am. Chem. Soc. 1996, 118, 9202; (b) Endo, A.; Yanagisawa, A.; Abe, M.; Tohma, S.; Kan, T.; Fukuyama, T. J. Am. Chem. Soc. 2002, 124, 6552; (c) Chan, C.; Heid, R.; Zheng, S.; Guo, J.; Zhou, B.; Furuuchi, T.; Danishefsky, S. J. J. Am. Chem. Soc. 2005, 127, 4596.

14 Myers, A. G.; Schnider, P.; Kwon, S.; Kung, D. W. J. Org. Chem. 1999, 64, 3322.

15 Jin, W.; Williams, R. M. Tetrahedron Lett. 2003, 44, 4635.

16 (a) De Paolis, M.; Chen, X.; Zhu, J. Synlett 2004, 729; (b) Wu, Y.-C.; Bernadat, G.; Masson, G.; Couturier, C.; Schlama, T.; Zhu, J. J. Org. Chem. 2009, 74, 2046.

17 Corey, E. J.; Xu, F.; Noe, M. C. J. Am. Chem. Soc. 1997, 119, 12414.

18 Recent excellent revews, see: (a) Maruoka, K. Org. Process Res. Dev. 2008, 12, 679; (b) Shirakawa, S.; Maruoka, K. Angew. Chem., Int. Ed. 2013, 52, 4312.

19 (a) Ooi, T.; Kameda, M.; Maruoka, K. J. Am. Chem. Soc. 1999, 121, 6519; (b) Ooi, T.; Kameda, M.; Tannai, H.; Maruoka, K. Tetrahedron Lett. 2000, 41, 8339; (c) Kitamura, M.; Shirakawa, S.; Maruoka, K. Angew. Chem., Int. Ed. 2005, 44, 1549; (d) Ooi, T.; Maruoka, K. Angew. Chem., Int. Ed. 2007, $46,4222$.

20 (a) Duff, J. C. J. Chem. Soc. 1932, 1987; (b) Razafindrabe, C. R.; Aubry, S.; Bourdon, B.; Andriantsiferana, M.; PelletRostaing, S.; Lemaire, M. Tetrahedron 2010, 66, 9061.

21 (a) Fujii, K.; Ikai, Y.; Oka, H.; Suzuki, M.; Harada, K.-i. Anal. Chem. 1997, 69, 5146.

22 (a) Fukuyama, T.; Sachleben, R. A. J. Am. Chem. Soc. 1982, 104, 4957; (b) Lane, J. W.; Lane, J. W.; Chen, Y.; Williams, R. M. J. Am. Chem. Soc. 2005, 127, 12684.

23 Kirschning, A.; Hahn, F. Angew. Chem., Int. Ed. 2012, 51, 4012. 


\section{Graphical Abstract}

To create your abstract, type over the instructions in the template box below.

Fonts or abstract dimensions should not be changed or altered.

Catalytic asymmetric synthesis of the common amino acid component in the biosynthesis of tetrahydroisoquinoline alkaloids

Leave this area blank for abstract info.

Ryo Tanifuji ${ }^{a}$, Hiroki Oguri, ${ }^{\text {a,b,c,* }}$ Kento Koketsu ${ }^{a}$, Yuki Yoshinaga ${ }^{a}$, Atsushi Minami ${ }^{a}$, Hideaki Oikawa ${ }^{a}, *$<smiles>[R]Cc1cc(OCc2ccccc2)c(OC)c(OC)c1[R]</smiles><smiles>CCOC(=O)CN=C(c1ccccc1)c1ccccc1</smiles>

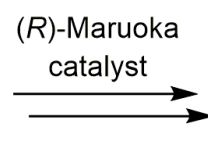<smiles>COc1c(O)cc(C[C@H](N)C(=O)O)cc1[N+](=O)[O-]</smiles><smiles>COc1c(O)cc(C[C@H](N)C(=O)O)c(OC)c1C</smiles> 